\title{
A constituição histórica do atendimento à pequena infância em Rio Grande/RS ${ }^{1}$
}

\begin{abstract}
Resumo
O presente artigo tem como objetivo analisar a constituição histórica do atendimento aos bebês e às crianças bem pequenas na cidade do Rio Grande/RS. O estudo foi desenvolvido a partir de aproximações com autores do campo pós-estruturalista que têm por bases os estudos foucaultianos. O período histórico abordado compreende acontecimentos do contexto imperial, devido aos indícios de que as primeiras formas de atendimento à infância rio-grandina começaram a se delinear nessa época. Ao descrever a categoria de análise, o estudo aponta que uma primeira forma de proveniência das práticas de atendimento à pequena infância em Rio Grande apresenta-se atrelada à caridade e a doutrinas religiosas, que fundamentadas em dogmas espirituais e transcendentes, pretendem conduzir a conduta dos homens.
\end{abstract}

Palavras-chave: Educação infantil - História. Creches. Rio Grande (RS).

\section{Para citar este artigo:}

BORGES, Juliana Diniz Gutierres; MOTA, Maria Renata Alonso. A constituição histórica do atendimento à pequena infância em Rio Grande/RS. Revista Linhas. Florianópolis, v. 20, n. 44, p. 233-256, set./dez. 2019.

\section{DOI: $10.5965 / 1984723820442019233$}

http://dx.doi.org/10.5965/1984723820442019233

\footnotetext{
${ }^{1}$ Este artigo é resultante de uma pesquisa financiada pela CAPES
}

\section{Juliana Diniz Gutierres Borges}

Universidade Federal de Pelotas UFPEL - Pelotas/RS - Brasil

julianadinizg@hotmail.com

\section{Maria Renata Alonso Mota}

Universidade Federal do Rio Grande - FURG - Rio Grande/RS - Brasil mariarenata.alonso@gmail.com 


\title{
The historical constitution of child care in Rio Grande / RS
}

\begin{abstract}
This article aims to analyze the historical constitution of the care of infants and young children, in the city of Rio Grande - RS. The study was developed based on approximations with post-structuralist authors based on the Foucaultian studies. The historical period covered includes events from the colonial context, due to the indications that the first forms of Rio-Grandina childcare began to be delimited at that time. In describing the category of analysis, the study points out that the first form of provenance of child care practices in Rio Grande is linked to charity and religious doctrines, which, based on spiritual and transcendental dogmas, are conduct the conduct of people.
\end{abstract}

Keywords: Early childhood education - History. Childcare. Rio Grande (RS). 
Este artigo é parte integrante de uma pesquisa que procurou analisar as práticas de atendimento às crianças de zero a três anos, que se desenvolveram ao longo do tempo e foram, pouco a pouco, constituindo possibilidades para a emergência da creche no Município do Rio Grande/RS. O presente estudo foi desenvolvido a partir de aproximações com autores do campo pós-estruturalista que têm por bases os estudos foucaultianos e tem por objetivo analisar a constituição histórica do atendimento à pequena infância em Rio Grande, com ênfase no Período Imperial brasileiro.

O período histórico escolhido compreende acontecimentos do século XIX, devido aos indícios de que as primeiras formas de atendimento à infância rio-grandina começaram a se delinear nessa época. O estudo aponta que até meados do século XIX, o atendimento à infância na cidade do Rio Grande caracterizou-se por uma fase caritativa. Esta permeou as práticas de assistência realizadas na época também em âmbito nacional. Conforme Marcilio (2003, p. 134), o que norteava essas práticas era o "sentimento da fraternidade humana, de conteúdo paternalista, sem pretensão a mudanças sociais". Já a partir do final da década de 1890, o assistencialismo é caracterizado por uma outra fase, denominada por Marcilio (2003), de filantrópica. Não se tratava mais de uma ação caritativa, mas de uma "filantropia [que] tinha por escopo preparar o homem higiênico (capaz de viver bem nas grandes cidades, em boa forma e com boa saúde), formar o bom trabalhador, estruturar o cidadão normatizado e disciplinado" (MARCILIO, 2003, p. 207).

Precisamos atentar para o fato de que que essa transição não se deu de forma imediata, mas gradualmente. Segundo Marcilio (2006, p. 78), "a caridade, confrontada com uma nova realidade econômica e social, foi absorvendo objetivos e táticas da filantropia”, enquanto que "a filantropia, por sua vez, não abandonou inteiramente os preceitos religiosos".

Sendo assim, ao olhar para o passado, este estudo procura historicizar determinadas práticas que se materializam em documentos e registros locais, procurando elencar novas problematizações para o presente. Para tanto, consiste em uma análise bibliográfica e documental, que teve como fonte primária a análise de jornais e documentos institucionais localizados em acervos do Município.

Para sustentar a análise, o estudo procura aproximar-se mais da genealogia, operando com conceitos centrais do domínio ser-poder. De acordo com Veiga-Neto 
(2003, p. 71), a genealogia se propõe a fazer "uma descrição da história das muitas interpretações que nos são contadas e que nos têm sido impostas. Com isso, ela consegue desnaturalizar, desessencializar enunciados que são repetidos como se tivessem sido descobertas e não invenções".

De acordo com Foucault, o objeto próprio da genealogia é marcado melhor por termos como proveniência e emergência do que origem. Assim, a genealogia, como análise da proveniência, está no ponto de articulação da superfície de inscrição dos acontecimentos com a história (FOUCAULT, 1979). Por isso, ela busca, na difusão dos acontecimentos, as diversas possibilidades de começo. Isso significa que esse tipo de estudo não procura desvelar o ponto originário que marca o único começo possível, mas busca as diversas condições que possibilitaram sua existência em um determinado contexto histórico-social. Tem-se, então, um entrecruzar de fatos, práticas, discursos, descontinuidades e dispersões. Em outras palavras, significa observar as heterogeneidades da história, e não a sua origem.

Seguindo essa perspectiva, ao questionar sobre a história do atendimento às crianças de zero a três anos no Município do Rio Grande, este estudo não tenciona localizar a gênese e a verdade que delimita seu único início possível. Ao contrário disso, procura buscar na história as distintas condições que possibilitaram a constituição das instituições de atendimento às crianças de zero a três anos.

Considerando que a história do atendimento à infância em Rio Grande não se deu de forma deslocada do âmbito nacional, este estudo apresenta uma contextualização histórica da Educação Infantil no Brasil, entrelaçando acontecimentos referentes ao atendimento da infância rio-grandina. Para tal, sentimos a necessidade de fazer uma breve contextualização acerca do município do Rio Grande, de forma a situar alguns acontecimentos para maior compreensão acerca das práticas de atendimento à infância ao longo dos tempos.

Rio Grande é um município do extremo sul do Rio Grande do Sul, situado entre a Lagoa Mirim, a Laguna dos Patos e o Oceano Atlântico. Possui área geográfica de $2.709,522 \mathrm{~km}^{2}$ e estima-se uma população de 207.036 habitantes. Em seu processo histórico, foi colonizado pelos portugueses açorianos, no século XVIII, sendo inicialmente chamado de Vila do Rio Grande de São Pedro. Somente no século seguinte foi que 
recebeu a denominação de Cidade do Rio Grande, momento em que passou a ser também o foco de outras imigrações, que viram na localidade um potencial para desenvolverem suas atividades econômicas.

A partir do século XIX, a industrialização da cidade começou a se desenvolver. Empresas pesqueiras foram instaladas no Município, tornando-se uma potente fonte econômica. Torres (2013) pontua que a história da cidade do Rio Grande é marcada por experiências de grande dimensão, porém com durações limitadas. Desse fato, segundo o autor, deriva certa instabilidade social, visto que há momentos em que contingentes populacionais são atraídos em busca de empregos, mas há outros em que essa contingência alimenta "uma periferia precária de uma urbanidade básica". Esses acontecimentos podem ser considerados como uma das condições de possibilidade para as primeiras iniciativas de atendimento aos bebês e às crianças bem pequenas no município do Rio Grande. É sobre isso que trataremos na próxima seção deste artigo.

\section{Apontamentos acerca do atendimento à infância: conexões entre o Brasil e Rio Grande}

O propósito desta seção é mostrar algumas transformações ocorridas nas práticas de atendimento à infância no decorrer da história. Não pretendemos fazer uma história totalitária da Educação Infantil, apenas destacar cenas que nos oportunizam compreender a forma como as práticas de atendimento às crianças pequenas foram, pouco a pouco, consolidando-se no Brasil e, mais especificamente, no Município do Rio Grande.

Para tanto, iniciaremos tecendo algumas aproximações com os estudos de Moysés Kuhlmann Júnior que, sem seguir uma linearidade temporal, faz uma análise do processo histórico das instituições de atendimento à infância, trazendo significativas contribuições para a análise que pretendemos realizar nesse momento. Conforme aponta o autor, as primeiras instituições desse tipo no Brasil inspiraram-se nos abrigos e asilos que, desde o período Medieval, recolhiam as crianças abandonadas. Nesse contexto, o surgimento dessas instituições foi fortemente marcado pelo propósito de conceder assistência e amparo aos desvalidos (KUHLMANN JR., 2011). 
Uma dessas primeiras iniciativas de atendimento aos bebês e às crianças bem pequenas foram as Rodas dos Expostos. Instaladas nos hospitais das Santas Casas de Misericórdia, serviram como uma alternativa para diminuir o número de crianças abandonadas pelas ruas.

O nome da roda provém do dispositivo onde se colocavam os bebês que se queriam abandonar. Sua forma cilíndrica, dividida ao meio por uma divisória, era fixada no muro ou na janela da instituição. No tabuleiro inferior e em sua abertura externa, o expositor depositava a criancinha que enjeitava. A seguir, ele girava a roda e a criança já estava do outro lado do muro. Puxava-se uma cordinha com uma sineta, para avisar a vigilante ou rodeira que um bebê acabava de ser abandonado e o expositor furtivamente retirava-se do local, sem ser identificado. (MARCILIO, 2006, p. 57)

Essa tradição, recorrente na Europa Medieval, instalou-se no Brasil pela primeira vez na cidade de Salvador (1726). Expandiu-se por outras cidades, como no Rio de Janeiro (1738) e em Recife (1789), chegando inclusive à Região Sul, como nos municípios de Rio Grande (1843) e de Pelotas (1849). Existindo por mais de dois séculos, no período compreendido entre 1726 e 1950, a Roda dos Expostos foi uma das instituições de atendimento mais duradouras no Brasil (MARCILIO, 2006). Cabe salientar que a sua principal preocupação, ao acolher a criança deixada nela, era providenciar o batismo, pois se acreditava que somente por meio deste a criança receberia a salvação da alma.

Nesse contexto, o surgimento dessas instituições foi fortemente marcado pelo propósito de conceder "assistência" e "amparo" aos desvalidos. Essas primeiras práticas de assistência à infância brasileira se desenvolveram por meio de ações de caridade realizadas pelas igrejas e conventos, no Período Colonial. Tais práticas podem ser entendidas como uma espécie de filantropia caritativa e ato de benemerência ao próximo, que objetivam conduzir as condutas dos sujeitos por meio das verdades religiosas que circulavam naquele contexto histórico (LOCKMANN; MOTA, 2013). 
Na Região Sul, essa iniciativa chegou à capital do estado em 1837 e, seis anos depois, estabeleceu-se no Hospital Santa Casa do Rio Grande. Antes dessa data, há indícios de que a Câmara Municipal já se encarregava desse serviço, tal como está registrado no jornal O Noticiador, primeiro jornal da Vila do Rio Grande de São Pedro:

Nesta Villa se tem edificado muito boas casas de sobrado, e outras se estão construindo com elegância e grandeza: alem disso, tem uma regular Aula Nacional de ensino mutuo, em um edificio proprio: tem uma escola particular de Meninas; [...] uma casa própria da Camara Municipal com sua competente Roda para Expostos... (JORNAL O NOTICIADOR, 1831, p. 5 , grifo nosso)

No ano seguinte, porém, outra nota foi emitida:

Roda de Expostos: A Camara Municipal desta Villa faz saber: que fallecendo lhe os meios para criação dos Expostos, por não ter rendimentos que possão fazer face ás despesas de pagamento das Amas, e outros indispensáveis: resolveu em Sessão de hoje, mandar pregar a roda, e não aceitar mais Expostos - E para que chegue ao conhecimento de todos, se mandou publicar, e affixar o presente nos lugares mais públicos. Anacleto José de Medeiros, presidente; Francisco José das Neves, secretario interino. (JORNAL O NOTICIADOR, 1832, p. 8)

Antes da roda, as crianças abandonadas deveriam ser, supostamente, atendidas pelas câmaras municipais. No entanto, as municipalidades frequentemente alegavam faltas de recursos e eximiam-se da responsabilidade pelos pequenos abandonados, serviço este que dava muito trabalho (MARCILIO, 2003).

Os dados da pesquisa sugerem que, após uma determinação da Câmara Municipal do Rio Grande, em 22 de dezembro de 1842, a Roda dos Expostos passa a ser administrada pela irmandade do Hospital Santa Casa do Rio Grande. Naquela época, as práticas de assistência à infância estavam vinculadas aos atos de boa vontade, e associavam-se à compaixão de nobres, religiosos e de instituições, como paróquias e hospitais, que se dedicavam a realizar ações caritativas em favor da criança abandonada. 
A coluna "Memória e História" do caderno O Peixeiro², de 07 de novembro de 2003, traz excertos do relatório das atividades da irmandade da Santa Casa de Misericórdia do Rio Grande, redigido pelo Irmão Provedor da Santa Casa Porfirio Ferreira Nunes, em 1861. A citação é um pouco extensa, mas oferece um panorama da situação dos expostos nesta cidade:

[...] O nosso estabelecimento de expostos teve princípio em julho de 1843. A Câmara Municipal era quem até então se encarregava deste serviço, que passou à Santa Casa por proposta da presidência da Província, de 22 de dezembro de 1842, e recebeu da Câmara duas meninas que continuaram a ser socorridas e um prédio sito à rua da Praia que produz anualmente $480 \$ 000$ réis de aluguel, único patrimônio que esta repartição possui. Desde que a Santa Casa tomou a seu cargo curar dos expostos, até 30 de junho de 1860, vieram à roda 139 crianças, 11 com aquelas duas que recebeu da Câmara, e mais 11 que a roda recebeu neste último ano compromissal, fazem o número de 152; sendo 78 do sexo feminino e 74 do masculino; 121 brancos, 23 pardos e 8 pretos. Foram reclamados por seus parentes 9 , ficaram maiores e a cargo das pessoas que os criaram 36, faleceram 81, existindo agora 26. Destes últimos, 15 são do sexo feminino e 11 do masculino; 23 brancos e 3 pardos. Destes, 9 percebem a mensalidade de $16 \$ 000$ réis e 17 a de $12 \$ 000$ réis, na forma estatuída. Nesta cidade criam-se em casas particulares 15, e fora delas 11. Pela estatística que vos apresento, tereis, como eu, de lastimar a extraordinária mortalidade destas infelizes criaturas, já este ramo de serviço havia ocupado a atenção de meus predecessores, que não puderam atingir o alvo que tanto desejavam, nem encontrar um remédio a tantas desgraças. [...]. Consola-nos poder reconhecer que temos alcançado salvar, em proporção guardada, maior número de expostos, dos quais nunca sobreviveram na Europa 40\%. Geralmente os expostos a cargo da Santa Casa são bem tratados e entregues a amas escolhidas. [...]. A Santa Casa, aceitando o convite que lhe fez a Presidência da Província em 1842, cumpriu um dever, contribuiu poderosamente para o bem-estar dos infelizes expostos e disso deve gloriar-se; porém, sendo diminuta a subvenção concedida pela Assembléia, priva a pobreza de uma quantia anual, que lhe é indispensável, diminui os seus recursos e lesa realmente os interesses da Santa Casa. (Relatório da Santa Casa de Misericórdia do Rio Grande, apud JORNAL O PEIXEIRO, 2003, p. 22)

Para compreendermos o surgimento dessa instituição na cidade do Rio Grande, é pertinente reiterar o contexto histórico vivido pelo país, na época. No Brasil Colônia, o abandono de bebês e crianças bem pequenas era uma prática frequente. Os pequenos

\footnotetext{
${ }^{2}$ O Jornal O Peixeiro começou a ser publicado em 1962 pela imprensa que atualmente é responsável pela publicação local do Jornal Agora. Desde 1975, O Peixeiro passou a ser editado como encarte cultural do Jornal Agora, com publicações semanais.
} 
eram deixados nas ruas, lixeiras, terrenos baldios ou portas de igrejas, sendo submetidos à fome, ao frio, entre outros fatores que os levavam a óbito caso não fossem encontradas a tempo, por pessoas caridosas que os recolhessem (VENÂNCIO, 1997). As condições miseráveis de vida da época não eram a única causa, inclusive, "mulheres de boa estirpe, também enjeitavam os filhos. Nesses casos, o gesto resultava da condenação moral e familiar frente aos amores proibidos" (VENÂNCIO, 1997, p. 192).

Neste contexto, o sistema de rodas de expostos seria "um meio encontrado para garantir o anonimato do expositor e assim estimulá-lo a levar o bebê que não desejava para a roda" (MARCILIO, 2003, p. 52). No relatório sobre a Casa da Roda de Rio Grande, temos um panorama geral da época e do propósito da instalação da roda no hospital Santa Casa:

[...] que falar dos Expostos, daquelas inocentes criaturas, que antes e depois de nascidas, bebem a longos sorvos na taça da desgraça, e talvez do crime que lhes propina o veneno, para ocultar uma vergonha antes desconhecida, onde os prazeres, as paixões, ou talvez o interesse encubram com flores os espinhos agudos, que deviam rasgar o véu de um falso pudor ou a venda com que se procura mascarar os resultados de um passo errado. Tudo é lícito supor da parte dos entes desalmados que abandonam à caridade pública seus inocentes filhos, frutos de amores ilícitos, da devassidão e da preguiça. Um crime prende sempre outro crime, e os prejuízos, que tanta influência têm na sociedade, aconselham muitas vezes um atentado oculto, para impedir a fronte de corar e conservar-se altiva, embora a consciência reprove pretensões, honras e respeitos unicamente devidos a virtude! A mortalidade em todas as partes onde existem estabelecimentos para a infância abandonada induz a crer que é devida a tentativas feitas antes de nascerem para delas verem-se livres as mães desalmadas que as geraram. Infanticídios estes, que não são provados porque os filhos mal manipulados, ou as doses despropositadas não preencheram os desejos e impediram a realização completa do crime: algumas horas de uma existência dúbia é bastante para lançar na roda os infelizes, salvar as aparências condenatórias e aumentar nos anais da Santa Casa o rol dos óbitos, atribuídos a falta de cuidados, ou vigilância dos empregados desta, quando a maior parte das criaturas beberam com a vida venenos lentos ou sofreram suplícios a que não eram condenadas, porque não pediram a existência aos entes bárbaros que lhes deram sem quererem conservá-la. É fora de dúvida que a mortalidade dos recém-nascidos, lançados na roda da Santa Casa, não pode ser atribuída a outras causas, que não sejam os maus tratamentos, a privação de alimentos necessários, ou os cálculos de evitar algumas despesas para os últimos deveres, pois que muitas destas criaturas têm expirado poucas horas depois de haverem sido recolhidas na roda. [...]. Com todo o desvelo me ocupei de prevenir a perda de tantas vidas; estudei todos os meios; 
observei as causas; consultei pessoas habilitadas e tenho de confessar que não pude atribuíla a outros motivos senão aos que aponto no princípio do relatório. Busquei até o estímulo no interesse, estabelecendo gratificações às amas durante os dois primeiros anos dos expostos, visitei-os e cuidei que não lhes faltasse, e pouco consegui; porque a substância principal falta aos recém-nascidos: os carinhos maternais, aqueles cuidados que o coração inspira e que por uma espécie de influência magnética se infiltram nas tenras criaturas, não podem ser supridos por amas de empréstimo e assalariadas. No entanto, devemos confessar que todos os nossos esforços não têm sido infrutíferos, atentas as dificuldades de meios e nosso atraso de conhecimento em tais materiais. (Relatório da Santa Casa de Misericórdia do Rio Grande, apud apud JORNAL O PEIXEIRO, 2003, p. 23)

Nesse excerto torna-se evidente o propósito da roda em funcionar como um dispositivo caritativo, que possibilitava às mães outra alternativa, que não fosse o aborto, o infanticídio nem o "abandono selvagem” (VENÂNCIO, 1997, p. 190)․ Assim, "a roda de expostos, como assistência caritativa, era, pois, missionária. A primeira preocupação do sistema para com a criança nela deixada era de providenciar o batismo" (MARCILIO, 2003, p. 54). Essa motivação de caráter religioso repercutiu intensamente por todo o período Imperial dando sustentabilidade às práticas de assistência caridosa para com as crianças atendidas nessa instituição.

Estando, assim, arraigada aos costumes e ensinamentos católico-cristãos, a roda configurou-se como prática de caridade e meio para a salvação das almas. Essas primeiras práticas de assistência eram guiadas pelo princípio da salvação divina alcançada por meio do batismo e da obediência aos doutrinamentos espirituais. Na concepção da época, essas práticas pretendiam salvar não somente os necessitados (salvando suas almas e suprindo suas necessidades básicas terrenas), mas também salvar (terrena e eternamente) aquele que prestava o auxílio (LOCKMANN, 2013). Tal concepção é nitidamente percebida na publicação do jornal A Imprensa, de 1858 , conforme o texto descrito abaixo:

Em janeiro deste anno falleceu no Porto, Joaquim Ferreira Brandão, negociante que foi de ferragens nesta cidade, e em seu testamento se lê

\footnotetext{
${ }^{3}$ Venâncio utiliza essa expressão para referir-se àquelas práticas de abandono de "meninos e meninas com dias ou meses de vida, deixados em calçadas, praias e terrenos baldios, conhecendo por berço os monturos, as lixeiras, e tendo por companhia cães, porcos e ratos que perambulavam pelas ruas" (1997, p. 190).
} 
as seguintes verbas: Deixo a Santa Casa de Misericórdia da cidade do Rio Grande do Sul do Imperio do Brasil, a quantia de 4:000\$ em moeda do mesmo Imperio. [...] Declaro que fui padrinho de baptismo de uma engeitada da roda da mesma cidade do Rio Grande do Sul, cujo nome ignoro, mas que há de constar dos livros e assentos da mesma roda, e a essa engeitada, minha afilhada, deixo 1:000\$ e se ella fôr morta, reverterá esta quantia á Santa Casa do Rio Grande. Estas deliberações do honrado finado é o testemunho mais nobre da alma pura e generosa de Brandão que ainda mesmo longe e há muito retirado do Rio Grande, não se esqueceo da terra onde fez a sua fortuna. Consta-nos que a Mesa da Santa Casa grata a esta generosa oferta deliberou que se celebrasse uma missa pela alma do honrado Joaquim Ferreira Brandão. (JORNAL A IMPRENSA, 1858, p. 15, grifo nosso)

Essa prática era comum na realidade brasileira da época, principalmente por ser um país fortemente influenciado pelo catolicismo e apregoar a caridade como fundamento da fé cristã. Por isso, "homens proprietários, preocupados com a salvação de suas almas, deixavam em seus testamentos legados e esmolas para a misericórdia, muitos designando-os expressamente para ajuda na criação dos expostos" (MARCILIO, 2003, p. 67).

Esse aspecto relacionado à filantropia caritativa pode ser articulado à metáfora do pastor de ovelhas, utilizada por Foucault. Na análise do autor, o pastoreio hebraico exercia um poder sobre o seu rebanho, conduzindo-o, alimentando-o, zelando por sua segurança e salvação. Para ele, "é esse tipo de poder que foi introduzido no Ocidente pelo cristianismo e que tomou uma forma institucional no pastorado eclesiástico: o governo das almas se constitui na Igreja cristã como uma atividade central e douta, indispensável à salvação de todos e de cada um" (FOUCAULT, 1987, p. 82).

É interessante atentar como esse poder pastoral foi tomando seus primeiros contornos e como foi se modificando e se intensificando no decorrer da história do cristianismo ocidental. Para os hebreus, o pastor era aquele que zelava pelas ovelhas, sendo sempre cuidadoso, vigilante e amoroso. Os hebreus associavam essas características do pastoreio à provisão divina, conforme consta no Salmo 23, cuja autoria atribui-se a Davi, monarca de Israel: "O Senhor é o meu pastor; nada me faltará. Deitar-me faz em verdes pastos, guia-me mansamente a águas tranquilas". Para os cristãos, textos do Novo Testamento bíblico aplicam essas características a Cristo. Um exemplo disso é a parábola do Bom Pastor, proferida por Jesus: "Eu sou o bom Pastor; o bom Pastor dá a 
sua vida pelas ovelhas. Mas o mercenário, que não é pastor, de quem não são as ovelhas, vê vir o lobo, e deixa as ovelhas, e foge; e o lobo as arrebata e dispersa. Ora, o mercenário foge, porque é mercenário e não tem cuidado das ovelhas. Eu sou o bom Pastor, e conheço as minhas ovelhas, e das minhas sou conhecido" (BÍBLIA, João, 10,11-14).

Essas características descritivas do pastoreio foram observadas por Foucault e, a partir delas, o filósofo tematizou sobre a forma como a Igreja ocidental passou a conduzir as condutas dos sujeitos através da pastoral das almas. Segundo o autor:

O pastor está a serviço do rebanho, deve servir de intermediário entre ele e os pastos, a alimentação, a salvação, o que implica que o poder pastoral, em si, é sempre um bem. Todas as dimensões de terror e de força ou de violência temível, todos esses poderes inquietantes que fazem os homens tremer diante dos poderes dos reis e dos deuses, pois bem, tudo isso se apaga quando se trata do pastor... (FOUCAULT, 2008, p. 172)

Assim, partindo da perspectiva foucaultiana, entendemos esse tipo de poder como uma forma de dirigir os sujeitos a partir da condução da consciência, da condução da alma. Para usar as palavras do autor, trata-se de "um tipo de poder bem específico que se dá por objeto a conduta dos homens - quero dizer, por instrumento os métodos que permitem conduzi-los e por alvo, a maneira como eles se conduzem, como eles se comportam" (FOUCAULT, 2008, p. 252). Assim, o poder pastoral se apresenta benevolente, zeloso pelo "bem-fazer" às ovelhas. É por isso que "ele não tem outra razão de ser senão fazer o bem", visto que "o objetivo essencial, para o poder pastoral, é a salvação do rebanho" (FOUCAULT, 2008, p. 170).

Com base nos escritos do filósofo, podemos perceber, por volta do século XVI, uma "intensificação do pastorado religioso em suas dimensões espirituais e em suas extensões temporais" (FOUCAULT, 2008, p. 308). A partir desse momento, o poder pastoral passou a ser significativamente intervencionista, influenciando a vida material, cotidiana e temporal dos indivíduos. Esse momento caracterizou-se por uma "assunção, pelo pastorado, de toda uma série de questões, de problemas referentes à vida material, à higiene, à educação das crianças" (FOUCAULT, 2008, p. 308). 
Assim, percebemos que uma primeira forma de proveniência das práticas de atendimento à infância - tanto em âmbito nacional quanto local - apresenta-se atrelada à caridade e a doutrinas religiosas, que fundamentadas em dogmas espirituais e transcendentes, pretendem conduzir a conduta dos homens nesse mundo. Como exemplo disso, podemos citar uma nota publicada, em 1859, no jornal Diário do Rio Grande, na qual está evidenciada com clareza a concepção de ação caritativa concernente aos expostos:

É certamente muito satisfatório para um paiz civilizado ter sociedades destinadas á alliviar ás dôres dos desgraçados que faltos de meios vêm-se privados de auxílios; para essas sociedades todas as classes são iguaes e as distinções são comuns; e os necessitados são attendidos com desvelos e carinhos. Na cidade do Rio Grande, temos preparado os alicerces de nova instituição benéfica, o que nós simpathisando altamente com as sociedades de caridade e beneficência publica, lhes agradecemos em nome dos que acharão nelas um allívio as penalidades do mundo, e como filho deste torrão nos congratulamos de ter no nosso seio corações desinteressados que praticam a verdadeira religião cuidando dos desvalidos. (JORNAL DIÁRIO DO RIO GRANDE, 1859, p. 30)

Entendemos que a crença na salvação eterna viabiliza o exercício desse poder, pois:

Na medida em que os homens estão mais preocupados com a sua salvação no outro mudo do que com isso que se passa aqui em baixo, na medida em que querem verdadeiramente serem salvos, eles permanecem tranquilos e é mais fácil governá-los. Quanto mais os homens estão preocupados com a sua salvação no além, mais é fácil aqui embaixo governá-los. (FOUCAULT, 2010, p. 58)

Para complementar essa análise, trazemos as ações de uma das criadeiras de expostos como exemplo de caridade e benemerência ao próximo, publicada no jornal Rio Grande:

Ignacia Rodrigues Ramos parteira desde recuardos anos, viu o desapontar de muitas gerações que hão de eternamente bendizer-lhe o nome [...]. Criava expostos da Santa Casa [...] e nessa árdua missão consumiu a maior parte de sua existência, constituindo-se uma benemérita do povo rio-grandense. (JORNAL RIO GRANDE, 1900, p. 12) 
O relatório, de 1854, do ex-provedor da Santa Casa José Cosme dos Reis também menciona outros exemplos de ações caritativas desenvolvidas em favor dos expostos:

Tendo-me requerido Rita Maria de Oliveira, residente na Villa de S. José do Norte, a concessão de uma exposta que tivesse de 2 para 3 annos de idade, não para crial-a á custa da Misericordia, mas sim gratuitamente por voto que fizeram por accasião de moléstia, submetti seu requerimento á consideração da mesa, que deliberou deferir-Ihe favoravelmente, e em consequência disto Ihe foi entregue a exposta n. 36 de nome Avelina, de $4 \frac{1}{2}$ anos de idade, a qual, não o recebia tratamento a que tinha direito sob a proteção da pessoa a quem estava confiada. Hoje tenho o prazer de anunciar-vos que esta orphan é cuidadosa e desvaladamente educada. Sorte igual, senão ainda melhor coube á exposta n. 6 de nome Amelia, que em 12 de agosto de 1844 foi tirada da roda por uma família respeitável, que a tomou debaixo da sua tutela desde os primeiros dias de sua existência. Tem sido creada sem os auxílios da Santa Casa, e actualmente se acha no Rio de Janeiro em um collegio, onde recebe brilhante educação que lhe promete ainda mais prospero futuro. (RELATÓRIO DO EX-PROVEDOR DA SANTA CASA JOSÉ COSME DOS REIS, 1854, p. 40)

Para compreendermos um pouco das práticas que envolviam o atendimento aos expostos dentro dessa lógica, destacamos a seguir alguns excertos do Regimento da Roda dos Expostos da Santa Casa do Rio Grande (1850). Dentre os aspectos trazidos nesse documento, está o papel da administração da repartição dos expostos e dos empregados envolvidos na criação dos enjeitados ${ }^{4}$ até completarem seis anos de idade.

A administração do sistema assistencial para as crianças expostas na Roda encarregava-se pela gestão econômica e dos funcionários responsáveis pela criação, educação e assistência médica dos expostos. $O$ artigo $2^{\circ}$ do Regimento especifica essa função:

Art. $2^{\circ}$. A estes administradores compete o governo administrativo e econômico dos negócios relativos aos expostos, obrando cada um per si nos casos de sua privativa competência ao diante declarados, e propondo de commum accôrdo ao provedor, para este levar ao conhecimento da mesa quando não lhe compita decidir definitivamente, tudo o que julgarem conveniente sobre o melhor modo de dirigir os mesmos negócios, em benefício do melhoramento e prosperidade da condição dos expostos. (JORNAL RIO GRANDE, 1850, p. 32)

\footnotetext{
4 "No Brasil, desde a colônia até a crise do império, no final do século XIX, a criança abandonada era tratada pelos termos "expostos" e "enjeitados". Esses termos correspondiam ao tipo de abandono mais comum para o período, qual seja, o de recém-nascidos, e se consubstanciavam nas práticas de enjeitar as crianças expondo-as em locais onde seriam, muito provavelmente, recolhidas" (TRINDADE, 1999, p. 3).
} 
O governo administrativo e econômico da roda era exercido pelo irmão mordomo. Cabia a ele inspecionar e velar pela criação e educação dos expostos entregues à Santa Casa. Ao tratar dos deveres e atribuições do irmão mordomo, o Regimento registra a preocupação em batizar as crianças expostas que não possuíam declaração de já o estarem, antes que saíssem da Roda.

Contudo, fazendo uma leitura atenta de todo o documento, veremos que, embora a grande motivação para o atendimento às crianças na roda tenha sido a salvação da alma dos recém-nascidos, buscava-se, também, salvar-lhes a vida, como se pode depreender no artigo citado a seguir:

Art. $10^{\circ}$, II, VIII. Compete e é do dever do irmão mordomo dos expostos:[...] Entregar as crianças ás amas externas, á vista dos despachos do provedor, verificando a identidade das pessoas a quem os referidos despachos iacumbirem a criação dos expostos [...] tendo sempre todo o cuidado para que estes sejão bem tratados, tanto por parte das amas no seu aleitamento, como pelo que diz respeito ao vestuário, curativo e asseio; e que o edifício, móveis e utensís se conservem constantemente no melhor estado de limpeza, as camas enxutas e decentes e as roupas bem lavadas. (JORNAL RIO GRANDE, 1850, p. 33)

O atendimento médico existente na roda também evidenciava essa preocupação. Aos médicos cabia:

Art. 23. [...] visitar o estabelecimento, ao menos uma vez por dia, no caso de haver algum exposto enfermo, e mais de uma vez, quando moléstias graves o exigirem; determinar o curativo dos expostos enfermos; dirigir o tratamento ordinário dos expostos no estado de saúde, indicando à regente e às criadeiras externas os alimentos que lhes forem mais convenientes, e a aplicação dos meios que a higiene aconselha para que se criem os expostos com saúde e robustez; inscrever os números e nomes dos expostos que adoecerem, em um livro que haverá na Santa Casa para esse fim, com designação das moléstias que padecerem e de que falecerem; acrescentando as observações que julgarem convenientes, e que possam servir para a estatística higiênica das moléstias dominantes nos expostos; vacinar os expostos, logo que por sua idade e saúde se achem em circunstâncias de poder receber a vacina. (JORNAL RIO GRANDE, 1850, p. 34) 
Assim, podemos compreender que as práticas de atendimento difundidas nessa instituição visavam a salvação do necessitado, oferecendo ajuda material como: alimento, roupas e medicamentos (salvação do corpo); e o batismo (salvação da alma).

No decorrer do documento, é possível perceber a organização de três momentos distintos no atendimento às crianças expostas: o primeiro, compreendendo os bebês, aleitados pelas amas-de-leite; o segundo, envolvendo as meninas de até seis anos e os meninos de até sete anos de idade, entregues às criadeiras; e o terceiro, abrangendo as crianças que completavam seis e sete anos, que passavam a ser educadas por pessoas que se dispunham a encarregar-se da tarefa gratuitamente. Podemos observar essa organização nos artigos a seguir:

Art. 30. Todos os expostos, sempre que seu estado o permitir, serão tratados na casa da roda, além do leite natural que puderem receber das amas, com amamentação artificial, e seguidamente com alimentos que se costumão dar às crianças em taes idades.

Art. 35. Os expostos serão tratados na casa da roda enquanto não aparecerem pessoas com a necessária capacidade, que queirão encarregar-se de sua criação, recebendo porisso a gratificação de dezesseis mil réis mensais até aos dezoito mezes de idade; e findos estes, a de doze mil réis por mez, até completarem a idade de seis anos as meninas e sete os varões.

Art. 46. Logo que as expostas tiverem completado seis anos de idade, e os varões sete, as pessoas encarregadas de sua criação devem declarar ao irmão mordomo se lhes convem ou não tel-os d'essa época em diante a seu cargo gratuitamente, com a condição de os educar da maneira que Ihes fôr indicada pela administração dos expostos. (JORNAL RIO GRANDE, 1850, p. 36)

Nos jornais locais, eram publicados anúncios sobre a procura por amas-de-leite:

Santa Casa de Misericódia. Procura-se uma ama de leite, para ser encarregada da creação de um exposto que se acha na casa da roda. $O$ mordomo A. J. Soares Viana. (JORNAL RIO GRANDE, 1866, p. 18)

O mordomo Antonio José Viana pela imprensa pede uma ama que esteja em boas condições para se encarregar da criação de um exposto recém nascido. (JORNAL RIO GRANDE, 1866, p. 18) 
Também eram emitidas notas sobre as crianças deixadas na Roda, bem como as indicações aos interessados em criar algum dos expostos.

A Santa Casa anuncia que na Casa dos Expostos existe uma creança para criar que será dada á pessoa que para isso se achar habilitada. O interessado deve dirigir-se a residência do Mordomo á rua da Praia 146. (JORNAL RIO GRANDE, 1848, p. 20)

Existe na Santa Casa uma exposta branca para se dar a crear; quem a pretender procure o mordomo das mesmas na rua da Praia $146,1^{\circ}$ andar. (JORNAL RIO GRANDE, 1848, p. 18)

Existe na Santa Casa uma exposta recém-nascida para se dar a crear; quem a pretender dirija-se ao mordomo dos expostos, rua da Praia 146. (JORNAL RIO GRANDE, 1866, p. 18)

Com base nessa separação etária, podemos perceber que a concepção de educação que aparece no Regimento dirigia-se às crianças maiores de seis anos e consistia em ensinar a ler, escrever e contar. O artigo $5^{\circ}$ aborda, com clareza, essa compreensão de educação:

Art. $5^{\circ}$. V. Proporcionar meios de educação aos expostos, logo que estes tenhão chegado à idade-de seis annos as meninas, e de sete os varões -, debaixo das seguintes, bases: Sendo varão, tratar-se-á de entregal-o à pessoa que o criou, se for capaz, obrigando-se esta, por termo que assignara perante a administração dos expostos, a mandal-o ensinar a ler, escrever e contar em alguma aula publica, e a prender qualquer officio ou indústria [...]. Sendo menina, tratar-se-á de deixal-a com a pessoa que a tiver criado, sendo honesta e capaz, e obrigando-se da maneira acima a mandal-a ensinar a ler, escrever e contar, coser, lavar e engomar. (JORNAL RIO GRANDE, 1850, p. 32)

Desde esse momento, começava-se a atribuir uma polaridade entre assistência e educação no atendimento à infância. Acreditava-se que o cuidado se vinculava ao atendimento às crianças de até seis anos e à educação às maiores. Outro fato relevante é que a maioria das crianças expostas tinha de zero a três anos. Esse dado demonstra a carência de outras instituições que atendessem a essa faixa etária, bem como a inexistência de políticas públicas para atender a essa demanda. 
É importante mencionar, ainda, que durante os 54 anos de sua existência, a Roda dos Expostos instalada na cidade do Rio Grande recebeu centenas de crianças, porém mais da metade dos enjeitados morria dias após serem postos na Roda. As condições que conduziram a esse elevado índice de mortalidade eram: o estado de saúde debilitado com que a maioria chegava à roda; a falta de cuidado de algumas amas-de-leite; e a terrível epidemia de cólera, que também não poupava os pequenos. Os que sobreviviam a esse quadro, eram criados na própria Santa Casa até chegarem à maioridade ou serem abrigados em casas de famílias (RODRIGUES, 1985).

Esses elevados índices de mortalidade dentro desta e de outras casas de expostos instaladas no país desencadearam, no final do século XIX, um movimento que visava a sua extinção. Médicos e higienistas mobilizaram-se em campanhas que apregoavam o seu fechamento. Essa situação implicou na necessidade de criação de outras instituições responsáveis pela sobrevivência dos enjeitados.

Devido à precariedade dos cuidados no atendimento aos expostos e considerando que a maioria das crianças expostas eram do sexo feminino, em 1861, foi instalado na cidade do Rio Grande o Asilo de Órfãs desvalidas Coração de Maria. Essa instituição foi planejada para auxiliar, complementar e, posteriormente, substituir o atendimento prestado na roda. Assim noticiou o Diário do Rio Grande, de 10 de agosto de 1861:

Comunicado - Um pensamento humanictário aparecceu n'esta cidade e achou eco na sua philantrópica população - qual seja um asylo para orphans desassistidas d'este município. Este pensamento, verdadeira inspiração emanação do céu, vai em breve ser realizado pelos esforços e dedicação de alguns varões estimáveis, intérpretes da Providencia, para quem o próprio impossível e' nada, quando se trata de um acto benemérito, com o concurso piedoso de todos, e sob o protetorado do nosso virtuoso prelado, Bispo d'esta província. Todos devem contribuir para tão santo fim [...] Santa Casa de Misericórdia creada para socorro dos míseros enfermos e amparos dos inocentes abandonados deve confraternizar-se. Lá educará suas expostas que também são orphans... (JORNAL DIÁRIO DO RIO GRANDE, 1861, p. 10)

Desde seu surgimento, as práticas realizadas no interior da instituição visavam amparar, educar e formar meninas órfãs da cidade, a partir das virtudes cristãs. Esse fato 
reitera a perspectiva de atendimento à infância rio-grandina como prática de caridade e meio para a salvação das almas. As rotinas do Asilo ilustravam esse propósito. Eram organizadas de forma a oportunizar às recém-nascidas o aleitamento, o batismo e os cuidados com o corpo; já às internas maiores, aulas de catequese, costura e bordado, práticas educativas, conhecimentos culinários, entre outras atividades.

Como podemos observar, o princípio norteador do pensamento da época possibilitava exercer um poder sobre a conduta dos rio-grandinos, com base na crença de uma vida após a morte. Apregoava-se à população a promessa da salvação, portanto, cabia aos interessados empenharem-se em serem suficientemente bondosos e solidários para alcançá-la, na eternidade. Dessa forma, por meio do discurso religioso, que instituía verdades sobre a população, era possível exercer o governo dos rio-grandinos. Tanto o atendimento realizado no Asilo Coração de Maria, quanto o prestado na Roda dos Expostos, podem ser compreendidos como práticas, através das quais a verdade religiosa se manifesta.

Sendo assim, as práticas de caridade e benemerência, que caracterizavam o atendimento à pequena infância naquele período, podem ser compreendidas dentro de uma conjuntura de regras e valores preponderantes que normatizavam a conduta da população. Essa verdade instituía e delimitava padrões morais de comportamento para aqueles que visavam a salvação eterna. É pertinente ressaltar que essa salvação tem também uma implicação terrena, na medida em que aparece como possibilidade para qualificar a vida do rio-grandino na Terra. Por esse motivo, podemos assim compreender que, em Rio Grande, as primeiras formas de atendimento aos bebês e às crianças bem pequenas operavam por meio da caridade e benignidade ao próximo com o propósito de salvar, aqui e no além, tanto o necessitado quanto o que presta o auxílio.

No que se refere à salvação da criança, cabe inferir ainda algumas análises. Para isso, trazemos as contribuições de Corazza (2000). Em seu estudo, intitulado $E$ os pequeninos, Senhor?, a autora analisa o discurso ocidental acerca do infantil, a partir de dois eixos: o de sua inocência e o da culpa efetiva. A autora examina alguns deslocamentos desses dois eixos no Sacramento do Batismo e na Pastoral Educativa, considerados pela autora como práticas de governamento da infância ou, em suas palavras, "governo dos infantis". 
Para o catolicismo romano, toda criança tinha uma mente a ser desenvolvida e uma alma a ser salva. "As crianças eram concebidas como socialmente marginais e como sujeitos aprisionados ao Pecado Original: naturalmente orientados ao mal, e necessitados de correção controle e formação" (CORAZZA, 2000, p. 79). Sendo assim, o sacramento do batismo operava - e ainda opera - como possibilidade de libertação do pecado, purificação e salvação. Ao serem batizadas, as crianças culpadas, passavam a ser lavadas do pecado, sepultando sua velha natureza pecaminosa, tornando-as finalmente inocentes. Desse modo,

Pelo batismo, as crianças nasciam de novo, não mais da família natural, e sim da família espiritual, cuja acolhida era imprescindível, porque as crianças não eram inocentes, haja vista a quantidade de sofrimentos que padecem [...] só o batismo abria "o caminho da salvação". (CORAZZA, 2000, p. 81)

Considerando, assim, a análise empreendida pela autora, compreendemos que o segundo eixo, o da "culpa", foi articulador das primeiras práticas de atendimento à infância rio-grandina. Esse eixo oportunizou "o exercício recorrente das relações do poder adulto com uma infância faltosa e carente" (CORAZZA, 2000, p. 69). Nesse contexto, segundo a autora, a vida da criança, seu corpo e sua alma são capturadas pelas instruções catequistas, pelo exame e pela condução contínua da consciência, instrumentos apropriados pelo cristianismo.

O estudo realizado por Senna (2012) oferece elementos que sustentam essa compreensão. Nele, a autora analisa as concepções de infância e criança que aparecem no Almanak Litterario e Estatístico do Rio Grande do Sul, no período de 1889 a 1899. Esse almanaque era uma publicação dessa cidade e frequentemente apresentava exposições sobre a infância. Analisando os primeiros dez anos de publicação, Senna (2012) percebe que algumas narrativas apontavam a natureza má das ações infantis. Dentre as histórias apresentadas pela autora está “A invejosa” (1890) e “Crueldade infantil” (1893):

Ao destacar o sentimento da inveja, o rio-grandino A. S. Pires, autor do texto, nos narra a história de uma menina com inveja [...] que fica furiosa e incorre em novos delitos. Segundo o autor por conta da "inveja" é que a menina piorou sua condição inicial e acredita ele "de quantos males não é ela a causa neste mundo!”. (SENNA, 2012, p. 192) 
O tema da crueldade infantil é relatado na proeza de uma menina que, às escondidas da mãe, abriu a gaiola do canário para ver a reação deste diante do gato que o espreita. A menina ainda é descrita como sanguinária e raivosa, uma vez que os ataques contra as pobres bonecas são sempre lastimáveis. (SENNA, 2012, p. 192)

Mais tarde, essa "culpa infantil" começa a fazer parte do pensamento ocidental que passa a ver a criança com as lentes da cientificidade. Tal concepção abre caminho para as práticas educacionais na instituição escolar.

\section{A pequena infância em Rio Grande: algumas considerações}

Ao analisar as primeiras práticas de atendimento à infância em Rio Grande, percebemos que determinadas representações sobre a criança e os modos de viver a infância foram sendo configurados no decorrer dos tempos. Tais representações estão relacionadas às transformações dos sentimentos e atitudes em relação à criança ao longo da história, na família e na sociedade.

Na Idade Média, por exemplo, não havia uma concepção particularizada de infância. A criança era tida como um adulto em miniatura. Não havia um sentimento ou consciência de infância quanto a sua especificidade (ARIÈS, 1981). Devido às condições de vida precárias na Idade Média, o índice de mortalidade era muito elevado. Disso se propagava a ideia de que "as pessoas não podiam se apegar muito a algo que era considerado uma perda eventual" (ARIÈS, 1981, p. 54). Daí o sentimento de indiferença com relação à infância.

É importante salientar que a visão medieval sobre a infância se perpetuou por muito tempo. Principalmente, porque encontrava sustentação na própria definição do termo.

A definição da palavra infância, oriunda do latim infantia, significa "incapacidade de falar". Considerava-se que a criança, antes dos 7 anos de idade, não teria condições de falar, de expressar seus pensamentos, seus sentimentos. Desde a sua gênese, a palavra infância carrega consigo o estigma da incapacidade, da incompletude perante os mais experientes, relegando-lhes uma condição subalterna diante dos membros adultos. Era um ser anônimo, sem um espaço determinado socialmente. (CORDEIRO; COELHO, 2007, p. 884) 
Percebemos essa concepção acerca da infância ao lermos os jornais antigos da cidade do Rio Grande. A maioria deles sequer faz menção à criança e à infância. Quando mencionam, trata-se de relatos sobre mortes. Tal como está expresso nos excertos abaixo, extraídos do jornal Diário do Rio Grande de 1874:

Obtuario - sepultaram-se no cemitério d'esta cidade: Dia 4/2. Manuel 14 mezes, branco, natural d'esta cidade, filho de Sebastiana Eulália de Lima. Diarréia.

Dia 17/3. Maria Francisca, 1 anno, branca natural d'esta cidade, exposta da Misericordia. Dsynteria.

Dia 17/6. Rita, $1 \frac{1}{2} \mathrm{mez}$, branca, natural d'esta cidade, exposta da Santa Casa. Affecção cerebral.

Dia 18/6. Maria, branca, natural d'esta provincia, filha de Ignez da Costa Freire. Ao nascer.

Dia 26/6. Manuel, 5 meses, pardo, filho da parda Joaquina, liberta. Ataque de congestão.

Para compor os excertos acima, selecionamos aqueles que fazem referência às crianças de zero a três anos. Foi possível perceber que a maior incidência de notas sobre os obituários compreendia essa faixa etária. As causas da morte iam desde diarreia até inanição, brochite capillar, ataque de congestão, entero-colite agudo e disenteria.

Como é possível observar, os registros encontrados são fundamentalmente sobre as mortes das crianças e certamente estiveram associados à invisibilidade política e econômica da criança como parte da população. Com isso entendemos que, mesmo em um período em que a infância passava por uma aparente invisibilidade, já se anunciava uma preocupação com a criança. Assim, a preocupação com a morte das crianças pode ser um dos fatores que possibilitou a entrada em cena de instituições extradomiciliares destinadas ao seu cuidado e educação no Município do Rio Grande. 


\section{Referências}

ARIÈS, Philippe. História social da criança e da família. Rio de Janeiro: LCT - Livros Técnicos e Científicos Editora S.A, 1981.

BÍBLIA. Evangelho segundo João. Português. Bíblia sagrada: contendo o antigo e o novo testamento. Tradução de João Ferreira de Almeida. Rio de Janeiro: Sociedade Bíblica do Brasil, 1966.

CORAZZA, Sandra Mara. E os pequeninos, Senhor? Inocência e culpa na pastoral educativa. Educação e Realidade, Porto Alegre: FACED/UFRGS, v.25, n.1, p. 59-92, dez/jul 2000.

CORDEIRO, Sandro da Silva; COELHO, Maria das Graças Pinto. Descortinando o conceito de infância na história: do passado à contemporaneidade. In: CONGRESSO LUSOBRASILEIRO DE HISTÓRIA DA EDUCAÇÃO, 6, 2007, Uberlândia, Anais [...]. Uberlândia: UFMG, 2007. p. 882-889

FOUCAULT, Michel. Microfísica do poder. Rio de Janeiro: Graal, 1979.

FOUCAULT, Michel. Vigiar e punir. 5 ed. Petrópolis: Vozes, 1987.

FOUCAULT, Michel. Segurança, território, população. São Paulo: Martins Fontes, 2008.

FOUCAULT, Michel. Do governo dos vivos: curso no Collège de France: 1979-1980:

excertos. São Paulo: Centro de Cultura Social; Rio de Janeiro: Achiamé, 2010.

IMPRENSA, A. Jornal. Rio Grande, 1858.

KOHAN, Walter. Infância: entre educação e filosofia. Belo Horizonte: Autêntica, 2003.

KUHLMANN JR., Moysés. Infância e educação Infantil: uma abordagem histórica. Porto Alegre: Mediação, 2011.

LOCKMANN, Kamila. A proliferação das políticas de assistência social na educação escolarizada: estratégias da governamentalidade neoliberal. 2013. 318f. Tese (Doutorado em Educação) - Universidade Federal do Rio Grande do Sul. Porto Alegre, 2013.

LOCKMANN, Kamila; MOTA, Maria Renata Alonso. Práticas de assistência à infância no Brasil: uma abordagem histórica. Revista Linhas, Florianópolis, v. 14, n. 26, jan./jun. 2013, p. $76-111$.

MARCILIO, Maria Luíza. A história social da criança abandonada. São Paulo: Hucitec, 2003. 
MARCILIO, Maria Luíza. A roda dos expostos e a criança abandonada na história do Brasil.1726-1950. In: Freitas, M. (org.). História social da infância no Brasil. São Paulo: Cortez, 2006, p. 51-78.

NOTICIADOR, O. Jornal. Vila do Rio Grande de São Pedro, 1832.

PEIXEIRO, O Caderno. In: Jornal Agora, Rio Grande, 2003.

RIO GRANDE, Diário do. Rio Grande, 1859, 1874, 1861.

RIO GRANDE. Jornal, Rio Grande, 1848, 1866, 1900.

RIO GRANDE. Relatório do ex-provedor da Santa Casa José Cosme dos Reis. Rio Grande, 1854 .

RIO GRANDE. Regimento da roda dos expostos da Santa Casa do Rio Grande. Rio Grande, 1850.

RODRIGUES, Sued de Oliveira. Santa Casa do Rio Grande: a saga da misericórdia. Rio Grande: FURG, 1985.

SENNA, Adriana Kivanski de. Ser criança ou pensar a criança? a infância no "Almanak Litterario e Estatístico do Rio Grande do Sul”. (1889-1899). Historiæ, Rio Grande, 2012, p.185-199.

TORRES, Luiz Henrique. A herança histórica de Rio Grande. Zero Hora, Porto Alegre, 2013.

VEIGA-NETO. Alfredo. Foucault e a Educação. Belo Horizonte: Autêntica, 2003.

VENANCIO, Renato Pinto. Maternidade Negada. In: PRIORE, Mary del (org.). História das mulheres no Brasil. São Paulo: Contexto, 1997. p. 189-222.

Recebido em: 13/11/2017 Revisões requeridas: 07/03/2018 Aprovado em: 25/06/2018

Universidade do Estado de Santa Catarina - UDESC Programa de Pós-Graduação em Educação - PPGE Revista Linhas

Volume 20 - Número 44 - Ano 2019 revistalinhas@gmail.com 